\title{
Comparison of Adipose Distribution Indices with Gold Standard Body Composition Assessments in the EMPA- REG H2H SU Trial: A Body Composition Sub-Study
}

\author{
Ian J. Neeland · Darren K. McGuire • Björn Eliasson · Martin Ridderstråle • \\ Cordula Zeller · Hans J. Woerle · Uli C. Broedl · Odd Erik Johansen
}

To view enhanced content go to www.diabetestherapy-open.com Received: October 13, 2015 / Published online: November 25, 2015

(C) The Author(s) 2015. This article is published with open access at Springerlink.com

\section{ABSTRACT}

Introduction: Excess adiposity contributes to cardiometabolic disease. Although adipose depots can be measured using imaging, implementation remains limited in practice. Data comparing surrogate indices of total and visceral adiposity with gold standard measurements in the context of a clinical trial population are lacking. We explored the relationships between adipose distribution indices and imaging assessments of body

Electronic supplementary material The online version of this article (doi:10.1007/s13300-015-0146-7) contains supplementary material, which is available to authorized users.

I. J. Neeland ( $\square)$

Department of Internal Medicine, Division of

Cardiology, University of Texas Southwestern

Medical Center, Dallas, TX, USA

e-mail: ian.neeland@utsouthwestern.edu

\section{K. McGuire}

Department of Internal Medicine, Division of Cardiology and Department of Clinical Sciences, University of Texas Southwestern Medical Center, Dallas, TX, USA

B. Eliasson

Sahlgrenska University Hospital, Gothenburg, Sweden composition using baseline data from the EMPA-REG H2H SU ${ }^{\mathrm{TM}}$ trial.

Methods: 118 participants from the Phase III trial of empagliflozin $25 \mathrm{mg}$ vs. glimepiride 1-4 mg enrolled in a dedicated sub-study underwent assessment of total fat and fat-free mass by dual x-ray absorptiometry $(n=93)$ and abdominal visceral (VAT) and subcutaneous adipose tissue by magnetic resonance imaging $(n=99)$. Correlations with waist circumference (WC), estimated total body fat (eTBF), index of central obesity (ICO), and visceral adiposity index (VAI) were assessed.

Results: eTBF was highly representative of total body fat (Spearman's $\rho=0.73, P<0.001$ ) but not associated with VAT. WC and ICO were strongly, and VAI to a lesser degree, correlated

M. Ridderstråle

Steno Diabetes Center, Gentofte, Denmark

C. Zeller

Boehringer Ingelheim Pharma GmbH \& Co. KG, Biberach, Germany

H. J. Woerle · U. C. Broedl

Boehringer Ingelheim Pharma GmbH \& Co. KG, Ingelheim, Germany

O. E. Johansen

Boehringer Ingelheim Norway KS, Asker, Norway 
with VAT $(\rho=0.66, \quad P<0.001 ; \quad \rho=0.52$, $P<0.001 ; \rho=0.24, P=0.02$, respectively).

Conclusion: These findings support the use of eTBF and WC or ICO as surrogate indices for total body fat and VAT, respectively, in the absence of gold standard imaging methodology.

Keywords: Body fat distribution; Empagliflozin; Obesity; Sodium glucose co-transporter 2 inhibitor; Visceral adipose tissue

\section{INTRODUCTION}

Total body fat content, as measured by dual X-ray absorptiometry (DXA), is highly correlated with multiple metabolic risk factors [1]. Intra-abdominal (visceral) adipose tissue (VAT) also influences cardiometabolic risk factors independent of total body fat and is a major risk factor for many of the cardiometabolic complications of obesity [2-6]. Although various adipose depots can be accurately measured using dedicated imaging techniques, implementation of these modalities remain limited in clinical practice due to high cost, radiation exposure, and prolonged scan time. Multiple surrogate indices of total and visceral adiposity have been developed that do not require advanced imaging, have been validated with metabolic outcomes, and are more readily applied in the clinical setting [7-9]. Furthermore, the individual parameters used to derive these indices can be applied across a broad spectrum of populations.

Empagliflozin (EMPA) is a potent and selective sodium glucose cotransporter 2 inhibitor [10]. In a Phase III, randomized, double-blind trial (EMPA-REG H2H SU ${ }^{\mathrm{TM}}$, ClinicalTrials.gov NCT01167881) in 1549 patients with type 2 diabetes (T2D), EMPA
$25 \mathrm{mg}$ daily as add-on to metformin for 104 weeks led to sustained reductions in Glycosylated hemoglobin (HbA1c), body weight [MMRM-adjusted mean change from baseline $-4.6 \quad(95 \%$ CI $-5.0,-4.2) \quad \mathrm{kg}$, $P<0.0001]$, and blood pressure compared with glimepiride 1-4 mg [11]. In an embedded, dedicated body composition sub-study, reductions in trunk fat, limb fat, total fat mass, VAT [adjusted mean change from baseline $-22.2(95 \% \mathrm{CI}-37.1,-7.4) \mathrm{cm}^{3}$, $P=0.004]$, and abdominal subcutaneous adipose tissue [SAT; adjusted mean change from baseline -40.0 (95\% CI $-58.9,-21.1$ ) $\left.\mathrm{cm}^{3}, P<0.0001\right]$ were demonstrated with EMPA compared with glimepiride [11]. EMPA has also been shown to reduce body weight and surrogate indices of total and visceral adiposity at 12 and 24 weeks among 3300 patients with T2D enrolled in five clinical trials [12].

Data comparing adipose distribution indices with gold standard body composition measurements within the context of an extensively phenotyped clinical trial population with highly standardized assessments are lacking. We aimed to explore the relationships between adipose distribution indices and direct imaging assessments of body composition using baseline data from the EMPA-REG H2H SU trial.

\section{METHODS}

The EMPA-REG H2H SU trial was a double-blind, randomized, active-control trial of EMPA $25 \mathrm{mg}$ daily vs. glimepiride 1-4 mg daily as add-on to metformin among adults with T2D and HbA1c concentrations of $7-10 \%$ for 104 weeks. All patients at sites choosing to contribute to a dedicated body composition sub-study were offered participation and signed 
separate informed consent forms. Whole body DXA and regional magnetic resonance imaging (MRI) scans (involving one axial slice from T1 sequence with and without fat suppression at the level of L4-L5 intervertebral disc) were performed [11]. Scans were obtained in a standardized manner and assessed by an independent reviewer. Using Spearman's rank correlation coefficients, we assessed the correlations between gold standard body composition assessments-total fat mass and fat-free mass based on DXA and abdominal VAT and SAT based on MRI-and indices of total and visceral adiposity at baseline. Indices assessed included waist circumference (WC, cm); estimated total body fat [eTBF; Young man's Christian association (YMCA) formula] [13, 14]: $100 \times(-98.42+[4.15 \times \mathrm{WC} \quad$ (in) $]-[0.082 \times$ weight (lbs.)])/weight for men and $100 \times(-76.76+[4.15 \times \mathrm{WC}]-[0.082 \times$ weight $]) /$ weight for women; index of central obesity (ICO): WC/height [9]; and visceral adiposity index (VAI) [15]: (WC $(\mathrm{cm}) /[39.68+$ $(1.88 \times \mathrm{BMI})]) \times(\mathrm{TG} / 1.03) \times(1.31 / \mathrm{HDL}-\mathrm{C})$ for men; $(\mathrm{WC} /[36.58+(1.89 \times \mathrm{BMI})]) \times(\mathrm{TG} / 0.81) \times$ (1.52/HDL-C) for women, where BMI is body mass index $\left(\mathrm{kg} / \mathrm{m}^{2}\right), \quad \mathrm{TG}$ is triglycerides $(\mathrm{mmol} / \mathrm{L})$ and HDL-cholesterol is high-density lipoprotein cholesterol $(\mathrm{mmol} / \mathrm{L})$. Correlations (positive or negative) were classified as negligible if $0.0-0.3$, mild if $0.3-0.5$, moderate if 0.5-0.7, and high if 0.7-0.9 [16]. For all statistical testing, a 2 -sided $P$ value $<0.05$ was considered statistically significant. All statistical analyses were performed using SAS version 9.2 software (SAS Corporation, Cary, NC).

\section{Compliance with Ethics Guidelines}

All procedures followed were in accordance with the ethical standards of the responsible committee on human experimentation (institutional and national) and with the Helsinki Declaration of 1964, as revised in 2013. Informed consent was obtained from all the patients for being included in the study.

\section{RESULTS}

Baseline characteristics of 118 patients with a baseline DXA $(n=93)$ or MRI $(n=99)$ scan are shown in Table 1. Patients with a baseline scan had a mean age of 55.6 years and were predominantly female and white. Body weight, WC, eTBF, ICO, and VAI were similar between DXA and MRI scanned groups.

WC was mildly correlated with percent total body fat (Spearman's $\rho=0.31, P=0.002$ ) and fat-free mass (Spearman's $\rho=0.44, P<0.001$ ) but moderately correlated with VAT (Spearman's $\rho=0.66, P<0.001$, Fig. 1a) and SAT (Spearman's $\rho=0.55, P<0.001$ ). eTBF was highly correlated with total body fat (Spearman's $\rho=0.73, P<0.001$, Fig. 1b) and moderately correlated with SAT (Spearman's $\rho=0.51, \quad P<0.001)$, but not significantly associated with VAT. ICO was moderately correlated with total body fat (Spearman's $\rho=0.61, P<0.001$ ), VAT (Spearman's $\rho=0.52$, $P<0.001$, Fig. 1c), and SAT (Spearman's $\rho=0.67, P<0.001$ ), but not with fat-free mass. VAI was negligibly correlated with VAT (Spearman's $\rho=0.24, \quad P=0.02$, Fig. 1d) and was not significantly associated with SAT.

\section{DISCUSSION}

In this post hoc analysis using a subset of the 1549 patients with T2D randomized to treatment with EMPA vs. glimepiride in the EMPA-REG H2H SU trial with baseline DXA or MRI, we found that eTBF (using sex-specific equations incorporating weight and $\mathrm{WC}$ ) was highly representative of total body fat mass by 
Table 1 Baseline characteristics of the study population with a baseline DXA or MRI scan

\begin{tabular}{|c|c|c|}
\hline Baseline characteristics & $\begin{array}{l}\text { Patients with a DXA } \\
\text { scan }(n=93)\end{array}$ & $\begin{array}{l}\text { Patients with an } \\
\text { MRI scan }(n=99)\end{array}$ \\
\hline Age (years) & $55.6(10.8)$ & $55.6(10.1)$ \\
\hline Male (\%) & 39 (41.9) & $46(46.5)$ \\
\hline \multicolumn{3}{|l|}{ Race (\%) } \\
\hline White & $74(79.6)$ & $81(81.8)$ \\
\hline Asian & $17(18.3)$ & $14(14.1)$ \\
\hline Black & $2(2.2)$ & $4(4.0)$ \\
\hline \multicolumn{3}{|l|}{ Time since T2D diagnosis (years) } \\
\hline$\leq 1$ & $12(12.9)$ & $9(9.1)$ \\
\hline$>1-5$ & $35(37.6)$ & $45(45.5)$ \\
\hline$>5-10$ & $27(29.0)$ & $23(23.2)$ \\
\hline$>10$ & $19(20.4)$ & $22(22.2)$ \\
\hline HbA1c (\%) & $8.19(1.02)$ & $8.20(0.99)$ \\
\hline Fasting glucose $(\mathrm{mg} / \mathrm{dL})$ & $159.3(45.9)$ & $161.7(47.2)$ \\
\hline Triglycerides (mg/dL) & $183.0(116.1)^{\mathrm{a}}$ & $216.3(259.6)^{\mathrm{d}}$ \\
\hline HDL cholesterol (mg/dL) & $46.4(10.6)^{\mathrm{a}}$ & $45.2(10.6)^{\mathrm{d}}$ \\
\hline LDL cholesterol (mg/dL) & $96.0(31.3)^{\mathrm{a}}$ & $97.4(32.0)^{\mathrm{e}}$ \\
\hline Total cholesterol $(\mathrm{mg} / \mathrm{dL})$ & $177.8(38.9)^{\mathrm{a}}$ & $181.5(43.7)^{\mathrm{d}}$ \\
\hline AST (U/L) & $26.7(19.4)^{\mathrm{a}}$ & $26.6(17.8)^{\mathrm{d}}$ \\
\hline $\operatorname{ALT}(\mathrm{U} / \mathrm{L})$ & $34.1(25.6)^{\mathrm{a}}$ & $34.9(25.4)^{\mathrm{d}}$ \\
\hline Body weight (kg) & $84.1(15.2)$ & $87.4(16.3)$ \\
\hline Body mass index $\left(\mathrm{kg} / \mathrm{m}^{2}\right)$ & $31.9(4.9)$ & $32.4(4.9)$ \\
\hline Waist circumference $(\mathrm{cm})$ & $103.9(12.1)$ & $106.1(12.3)$ \\
\hline Est total body fat (\%) & $37.4(9.9)$ & $37.1(9.6)$ \\
\hline Index of central obesity & $0.64(0.08)$ & $0.65(0.08)$ \\
\hline Visceral adiposity index & $3.3(3.1)^{\mathrm{a}}$ & $4.4(8.5)^{\mathrm{d}}$ \\
\hline Total fat mass $(\%)$ & $38.4(8.4)$ & $38.9(8.0)^{\mathrm{b}}$ \\
\hline Fat-free mass $(\mathrm{kg})$ & $50.8(10.7)$ & $50.7(11.2)^{b}$ \\
\hline Visceral fat mass $\left(\mathrm{cm}^{2}\right)$ & $164.1(81.3)^{b}$ & $174.0(80.7)$ \\
\hline Abdominal subcutaneous fat mass $\left(\mathrm{cm}^{2}\right)$ & $338.4(107.6)^{c}$ & $342.2(111.4)$ \\
\hline
\end{tabular}

Data are mean (standard deviation) or $n(\%)$.

$D X A$ dual x-ray absorptiometry, MRI magnetic resonance imaging, T2D Type 2 diabetes, HbAlc glycosylated hemoglobin, $H D L$ high-density lipoprotein, $L D L$ low-density lipoprotein, $A S T$ Aspartate transaminase, $A L T$ Alanine transaminase Subjects with data available: ${ }^{\mathrm{a}} n=92 ;{ }^{\mathrm{b}} n=74 ;{ }^{\mathrm{c}} n=73 ;{ }^{\mathrm{d}} n=98 ;{ }^{\mathrm{e}} n=97$ 

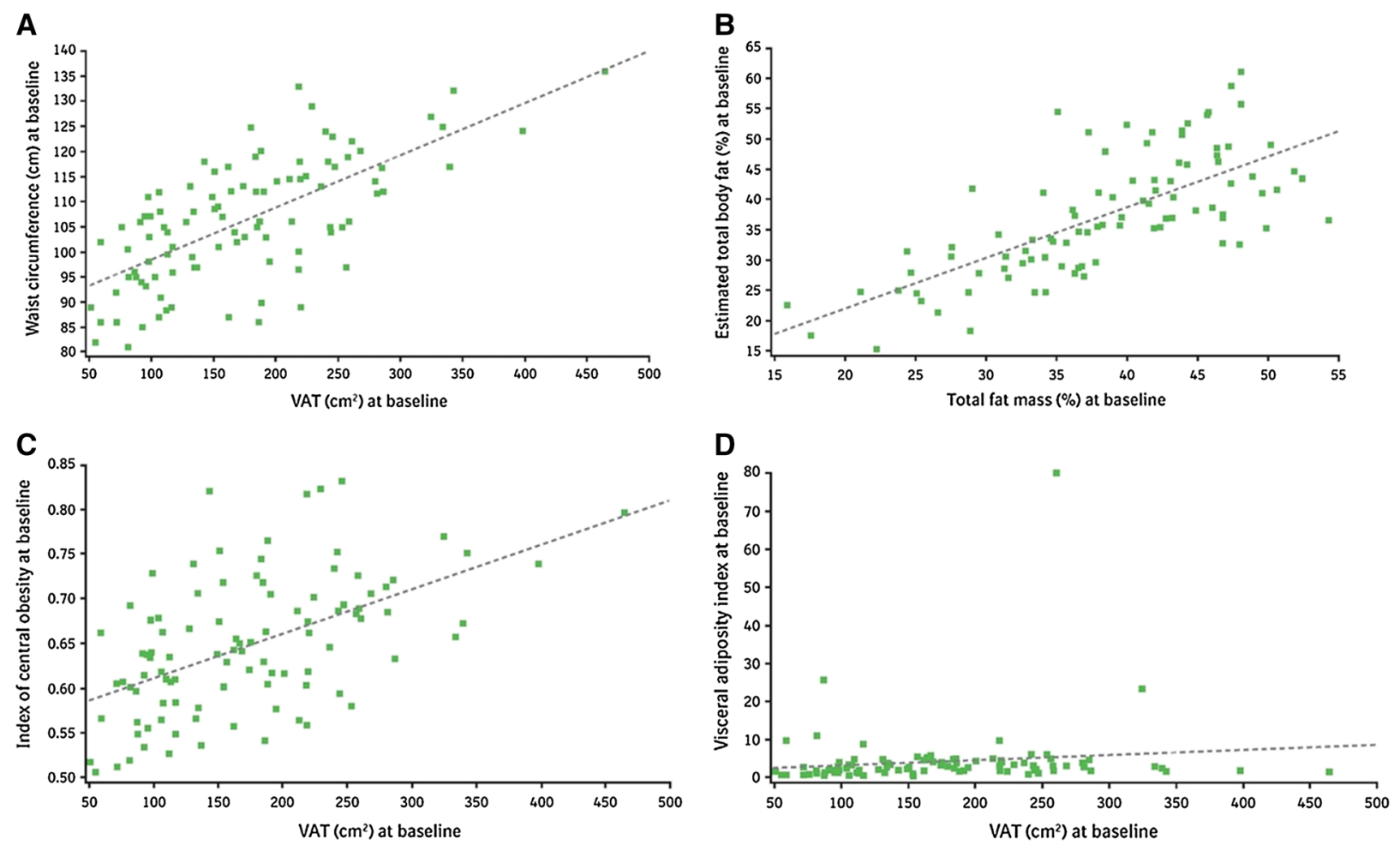

Fig. 1 Correlations between a waist circumference and VAT; $\mathbf{b}$ estimated total body fat and total fat mass by DXA; $\mathbf{c}$ index of central obesity and VAT; and $\mathbf{d}$ visceral

DXA, but not associated with visceral adiposity by MRI. By contrast, WC and ICO had the strongest relation to regional abdominal adiposity with VAT and SAT. Surprisingly, VAI was not highly correlated with MRI-based assessment of VAT. These findings support the use of eTBF for non-imaging estimations of total body fat and the use of WC or ICO as surrogate indices for abdominal VAT and SAT for both clinical and research purposes in the absence of gold standard methodology.

The eTBF index used in this study derives from the popularly termed YMCA formula, referencing the community fitness organization for which these formulas were once likely utilized in a training handbook. The origin of the eTBF index can be traced to the research of Wilmore and Behnke who used anthropometric measurements from multiple

adiposity index and VAT. $D X A$ dual x-ray absorptiometry, $V A T$ visceral adipose tissue

body sites to estimate body composition variables from regression equations among healthy college student volunteers [13, 14]. eTBF is relatively simple to calculate and is one of many anthropometry-based estimated body fat formulas currently in use. Our finding that eTBF was strongly correlated with total body fat by DXA, but not significantly associated with VAT by MRI (despite incorporation of WC as a derivation variable), supports its use as a surrogate for total body fat, but not abdominal adiposity, in the absence of DXA imaging. Whether eTBF is a better predictor of total body fat compared with other methods of body fat quantification remains to be seen.

WC has traditionally been considered one of the most valid indices of regional adipose tissue distribution with excellent correlation with 
VAT by abdominal imaging (correlation coefficient $=0.77$ among 151 metabolically healthy men and women) [17]. It also has a strong association with cardiovascular disease risk and mortality [18]. As a result, the American Heart Association/National Heart, Lung, and Blood Institute has incorporated WC as a surrogate marker of abdominal/central obesity in their diagnostic definition of the metabolic syndrome [19]. ICO, the index of WC to height, has also been extensively studied and may be superior to $\mathrm{WC}$ in predicting multiple cardiovascular risk factors in both sexes and different ethnic groups [20]. However, WC is limited as a surrogate for the VAT phenotype. First, the correlation between WC and VAT is highly variable among different racial groups, prompting the International Diabetes Federation to define different cutoffs for abnormal WC in Asian populations [21]. Nevertheless, we still observed a strong correlation between WC and VAT in our population with a significant proportion of Asian patients. Second, WC measurement includes both VAT and abdominal SAT compartments. These two depots are anatomically and physiologically distinct, especially within the obese population, and are differentially associated with markers of cardiometabolic risk [3]. Nevertheless, our findings demonstrate strong correlations between WC and ICO and VAT among an ethnically diverse population with T2D, supporting their use when direct imaging assessments are not available.

VAI is a mathematical model-derived index based on both anthropometric and laboratory-based correlates of excess adiposity. It has been shown to positively associate with peripheral glucose utilization during euglycemic hyperinsulinemic clamp and (expectedly given its derivation) is correlated with cardiovascular risk [15]. However, we found that the correlation between VAI and VAT as assessed by MRI was negligible, suggesting it does not sufficiently reflect the anatomic burden of VAT to warrant its use as a surrogate for clinical or research purposes. Further research should confirm these findings in varying populations with different demographic and clinical phenotypes.

Several study limitations merit comment. First, we are unable to report on the association of waist-hip ratio with direct imaging phenotypes as hip circumference was not measured in our study. Second, subgroup analyses by sex and age were not performed due to a limited sample size and the concern that multiple subgroup analyses on a limited patient sample may substantially increase the probability of false-positive findings [22]. Further research should focus on validating these indices within larger, more diverse populations, including age- and sex-specific analyses given their strong influence on adipose distribution.

\section{CONCLUSIONS}

In conclusion, using baseline data from the EMPA-REG H2H SU trial, we found strong correlations between the adipose distribution indices of eTBF (YMCA formula) and total body fat by DXA and between WC and ICO and abdominal VAT and SAT by MRI. These findings support their use as surrogate measurements for clinical and research purposes in the absence of gold standard direct imaging assessments of body fat composition. Analyses of the recently reported EMPA-REG OUTCOME ${ }^{\mathrm{TM}}$ trial (NCT01131676) [23] demonstrating decreased cardiovascular mortality of EMPA compared with placebo in a high-cardiovascular risk patient 
population may establish whether changes in such indices after EMPA treatment are associated with improved clinical outcomes.

\section{ACKNOWLEDGMENTS}

Boehringer Ingelheim (Ingelheim, Germany) and Eli Lilly (Indianapolis, IN) sponsored the clinical trial that this analysis is based upon. Boehringer Ingelheim provided sponsorship for article processing charges.

Ian J. Neeland is supported by grant 1K23DK106520-01 from the National Institute of Diabetes and Digestive and Kidney Diseases/ National Institutes of Health and as a Dedman Family Scholar in Clinical Care at UT Southwestern.

All named authors meet the International Committee of Medical Journal Editors (ICMJE) criteria for authorship for this manuscript, take responsibility for the integrity of the work as a whole, and have given final approval to the version to be published.

Disclosures. Darren K. McGuire reports research support and consultancy honoraria from Boehringer Ingelheim, Lilly USA, Janssen Research and Development LLC, Sanofi Aventis Groupe, Genentech, Inc., Merck Sharp and Dohme Corp., Daiichi Sankyo, Inc., Novo Nordisk, GlaxoSmithKline, Takeda Pharmaceuticals North America, Bristol-Myers Squibb, AstraZeneca, Orexigen, Lexicon, Eisai, Regeneron, Pfizer, and Genfit.

Martin Ridderstråle reports lecture honoraria from AstraZeneca, Boehringer Ingelheim, Novo Nordisk, Sanofi-Aventis, Novartis, Eli Lilly, Roche, Johnson\&Johnson, Merck, Medtronic, and GlaxoSmithKline.

Cordula Zelleris is an employee of Boehringer Ingelheim.
Hans J. Woerleis is an employee of Boehringer Ingelheim.

Uli C. Broedl is an employee of Boehringer Ingelheim.

Odd Erik Johansen is an employee of Boehringer Ingelheim.

Ian J. Neeland and Björn Eliasson have nothing to disclose.

Compliance with ethics guidelines. All procedures followed were in accordance with the ethical standards of the responsible committee on human experimentation (institutional and national) and with the Helsinki Declaration of 1964, as revised in 2013. Informed consent was obtained from all the patients for being included in the study.

Open Access. This article is distributed under the terms of the Creative Commons Attribution-NonCommercial 4.0 International License (http://creativecommons.org/licenses/ by-nc/4.0/), which permits any noncommercial use, distribution, and reproduction in any medium, provided you give appropriate credit to the original author(s) and the source, provide a link to the Creative Commons license, and indicate if changes were made.

\section{REFERENCES}

1. Vega GL, Adams-Huet B, Peshock R, Willett D, Shah $\mathrm{B}$, Grundy SM. Influence of body fat content and distribution on variation in metabolic risk. J Clin Endocrinol Metab. 2006;91:4459-66.

2. Despres JP. Body fat distribution and risk of cardiovascular disease: an update. Circulation. 2012;126:1301-13.

3. Neeland IJ, Ayers CR, Rohatgi AK, et al. Associations of visceral and abdominal subcutaneous adipose tissue with markers of cardiac and metabolic risk in obese adults. Obesity (Silver Spring). 2013;21:E439-47. 
4. Neeland IJ, Gupta S, Ayers CR, et al. Relation of regional fat distribution to left ventricular structure and function. Circ Cardiovasc Imaging. $2013 ; 6: 800-7$.

5. Neeland IJ, Turer AT, Ayers CR, et al. Dysfunctional adiposity and the risk of prediabetes and type 2 diabetes in obese adults. JAMA. 2012;308:1150-9.

6. Neeland IJ, Turer AT, Ayers CR, et al. Body fat distribution and incident cardiovascular disease in obese adults. J Am Coll Cardiol. 2015;65:2150-1.

7. Luo W, Guo Z, Wu M, Hao C, Zhou Z, Yao X. Index of central obesity as a parameter to replace waist circumference for the definition of metabolic syndrome in predicting cardiovascular disease. J Cardiovasc Med (Hagerstown). 2014;15:738-44.

8. Parikh RM, Mohan V. Changing definitions of metabolic syndrome. Indian J Endocrinol Metab. 2012;16:7-12.

9. Parikh RM, Joshi SR, Pandia K. Index of central obesity is better than waist circumference in defining metabolic syndrome. Metab Syndr Relat Disord. 2009; 7:525-7.

10. McGill JB. The SGLT2 inhibitor empagliflozin for the treatment of type 2 diabetes mellitus: a bench to bedside review. Diabetes Ther. 2014;5:43-63.

11. Ridderstrale M, Andersen KR, Zeller C, Kim G, Woerle HJ, Broedl UC. Comparison of empagliflozin and glimepiride as add-on to metformin in patients with type 2 diabetes: a 104-week randomised, active-controlled, double-blind, phase 3 trial. Lancet Diabetes Endocrinol. 2014;2:691-700.

12. Neeland IJ, McGuire DK, Chilton B, Crowe S, Lund SS, Woerle HJ, Broedl UC, Johansen OE. Empagliflozin reduces body weight and indices and adipose distribution in patients with type 2 diabetes mellitus. Diabetes Vasc Dis Res. 2015. (In Press).

13. Wilmore JH, Behnke AR. An anthropometric estimation of body density and lean body weight in young men. J Appl Physiol. 1969;27:25-31.

14. Wilmore JH, Behnke AR. An anthropometric estimation of body density and lean body weight in young women. Am J Clin Nutr. 1970;23:267-74.
15. Amato MC, Giordano C, Galia M, et al. Visceral adiposity index: a reliable indicator of visceral fat function associated with cardiometabolic risk. Diabetes Care. 2010;33:920-2.

16. Mukaka MM. Statistics corner: a guide to appropriate use of correlation coefficient in medical research. Malawi Med J. 2012;24:69-71.

17. Pouliot MC, Despres JP, Lemieux S, et al. Waist circumference and abdominal sagittal diameter: best simple anthropometric indexes of abdominal visceral adipose tissue accumulation and related cardiovascular risk in men and women. Am J Cardiol. 1994;73:460-8.

18. Coutinho T, Goel K, Correa de Sa D, et al. Combining body mass index with measures of central obesity in the assessment of mortality in subjects with coronary disease: role of "normal weight central obesity". J Am Coll Cardiol. 2013;61:553-60.

19. Grundy SM, Cleeman JI, Daniels SR, et al. Diagnosis and management of the metabolic syndrome: an American heart association/national heart, lung, and blood institute scientific statement. Circulation. 2005;112:2735-52.

20. Lee CM, Huxley RR, Wildman RP, Woodward M. Indices of abdominal obesity are better discriminators of cardiovascular risk factors than BMI: a meta-analysis. J Clin Epidemiol. 2008;61:646-53.

21. Alberti KG, Eckel RH, Grundy SM, et al. Harmonizing the metabolic syndrome: a joint interim statement of the international diabetes federation task force on epidemiology and prevention; national heart, lung, and blood institute; American heart association; world heart federation; international atherosclerosis society; and international association for the study of obesity. Circulation. 2009;120:1640-5.

22. Wang R, Lagakos SW, Ware JH, Hunter DJ, Drazen JM. Statistics in medicine-reporting of subgroup analyses in clinical trials. $\mathrm{N}$ Engl J Med. 2007;357:2189-94.

23. Zinman B, Wanner C, Lachin JM, et al. Empagliflozin, cardiovascular outcomes, and mortality in type 2 diabetes. N Engl J Med. 2015. doi:10.1056/NEJMoa1504720. 